\title{
Prognostic and Health Management of Active Assets in Nuclear Power Plants
}

\author{
Vivek Agarwal ${ }^{1}$, Nancy Lybeck ${ }^{1}$, Binh T. Pham ${ }^{1}$, Richard Rusaw ${ }^{2}$, and Randall Bickford ${ }^{3}$ \\ ${ }^{1}$ Idaho National Laboratory, Idaho Falls, ID, 83415, USA \\ vivek.agarwal@inl.gov \\ nancy.lybeck@inl.gov \\ binh.pham@inl.gov \\ ${ }^{2}$ Electric Power Research Institute, Charlotte, NC, 28262, USA \\ rrusaw@epri.com \\ ${ }^{3}$ Expert Microsystems, Orangevale, CA, 95662, USA \\ rbickford@expmicrosys.com
}

\begin{abstract}
This paper presents the development of diagnostic and prognostic capabilities for active assets in nuclear power plants (NPPs). The research was performed under the Advanced Instrumentation, Information, and Control Technologies Pathway of the Light Water Reactor Sustainability Program. Idaho National Laboratory researched, developed, implemented, and demonstrated diagnostic and prognostic models for generator step-up transformers (GSUs). The Fleet-Wide Prognostic and Health Management (FW-PHM) Suite software developed by the Electric Power Research Institute was used to perform diagnosis and prognosis. As part of the research activity, Idaho National Laboratory implemented 22 GSU diagnostic models in the Asset Fault Signature Database and two wellestablished GSU prognostic models for the paper winding insulation in the Remaining Useful Life Database of the FW-PHM Suite. The implemented models along with a simulated fault data stream were used to evaluate the diagnostic and prognostic capabilities of the FW-PHM Suite. Knowledge of the operating condition of plant asset gained from diagnosis and prognosis is critical for the safe, productive, and economical long-term operation of the current fleet of NPPs. This research addresses some of the gaps in the current state of technology development and enables effective application of diagnostics and prognostics to nuclear plant assets.
\end{abstract}

\footnotetext{
Agarwal et al. This is an open-access article distributed under the terms of the Creative Commons Attribution 3.0 United States License, which permits unrestricted use, distribution, and reproduction in any medium, provided the original author and source are credited.
}

\section{INTRODUCTION}

Currently in the United States there are 100 commercial nuclear power plant (NPP) units in operation providing $19 \%$ of the total electricity consumed by the nation (World, 2015). The average age of these existing NPPs is around 35 years. The United States Nuclear Regulatory Commission (USNRC) limits commercial power reactor licenses to an initial 40-year period with operating license renewals available for an additional 20 years. More than two-thirds of the existing commercial NPPs have received license extensions to 60 years, with no established cap on the number of 20 -year renewals the NRC may provide. In light of the fact that the USNRC expects the first application for subsequent license renewal (to 80 years) to be submitted as early as $\mathbf{2 0 1 7}$, the significant challenges associated with the continuous operation of NPP units beyond 60 years must be carefully considered. As plant structures, systems, and components age, their useful life-accounting for both structural integrity and performance - is reduced as a result of age- and operation- related deterioration.

To ensure long-term operation of the nation's current fleet of NPPs, the U.S. Department of Energy's Office of Nuclear Energy funds the Light Water Reactor Sustainability (LWRS) Program to develop the scientific basis for extending the operation of commercial light water reactors beyond the current 60 -year license period. The program is operated in collaboration with the Electric Power Research Institute's (EPRI's) research and development (R\&D) efforts in the Long-Term Operations (LTO) Program. Both the LWRS and LTO programs work closely with nuclear utilities to conduct $\mathrm{R} \& \mathrm{D}$ in technologies that can be used to 
ensure the long-term reliability, productivity, safety, and security of aging light water reactors.

It is important to understand the current condition of plant assets and be proactive in maintenance and replacement to improve plant reliability and productivity, and to reduce operational cost. The current periodic and condition-based maintenance practices at NPPs result in high maintenance costs and increased likelihood of human error, primarily due to unexpected component failure and forced outages resulting from failure to identify developing faults. To enhance current maintenance practices at NPPs, there is a movement towards online monitoring of the performance of plant assets. This includes transition from periodic manual assessments and surveillances of physical components and structures to centralized online condition monitoring across the fleet.

The Electric Power Research Institute has developed the Fleet-Wide Prognostic and Health Management (FW-PHM) Suite software to facilitate the implementation of diagnostics and prognostics throughout the power industry. EPRI is in the process of installing the FW-PHM Suite at nuclear utilities and developing a pilot application to demonstrate the technology. Deployment of FW-PHM in the nuclear industry is an important transformational step, enabling real-time assessment and monitoring of physical systems and better management of active assets (electromechanical components such as pumps, motors, emergency diesel generators, transformers, and turbines) based on their performance. The main contribution of this paper is summarizing the overall research, development, and implementation of fault signatures, and diagnostic and prognostics models for generator step-up transformers (GSUs) in FW-PHM. The implemented GSU models, along with simulated fault data, were used to evaluate the diagnostic and prognostic capability of the FW-PHM Suite.

The paper is organized as follows. Section 2 summarizes relevant work in the fleet-wide implementation of diagnostics and prognostics. Section 3 describes the FWPHM Suite software. Development and implementation of GSU diagnostic models are presented in Section 4. Section 5 describes the process of using the FW-PHM Suite to diagnose primary winding insulation degradation. Two prognostic models used to estimate the transformer winding insulation degradation are described in Section 6. Section 7 presents the process of using the FW-PHM Suite to estimate the remaining useful life (RUL) of GSU winding insulation. Discussion of the significance of this key research and its future benefits is presented in Section 8. Conclusions and future research directions are summarized in Section 9.

\section{RELATED WORKS}

Fleet-wide diagnosis, prognosis, and knowledge management have gained significant interest across different industries. A myriad of fleet-wide diagnosis and prognosis architectures, knowledge structures, and associated issues are reported in literature. Some relevant works are reviewed below.

Johnson $(2012,2014)$ discusses the challenges associated with the deployment of a fleet-wide health management solution, advocating a systematic approach in the design and deployment of the system. This approach includes identifying assets and business needs, pinpointing critical components within assets, choosing sensory sources, and selecting prognostic methods. In the case of transformers, Abu-Elanien and Salama (2010) present a comprehensive overview of transformer asset management. They discuss various condition monitoring techniques used to monitor and assess the condition of the transformer.

Monnin, Voisin, Leger, and Lung (2011) point towards the significance of managing relevant knowledge arising both from modeling and monitoring of the fleet. Medina-Oliva, Voisin, Monnin, Peysson, and Leger (2012) present a knowledge-structuring scheme based on ontologies that was developed for fleet-wide application of PHM. In the case of fleets with heterogeneous assets, Monnin, Abichou, Voisin, and Mozzati (2011) use the knowledge-structure based on ontologies to search for assets based on similar characteristics. Patrick, Smith, Byington, Vachtsevanos, Tom, and Ly (2010) argue that the threshold values indicating different fault conditions for a homogeneous fleet could be derived from statistical studies of fleet-wide behaviors of identical assets and known cases of faults. Wang, Yu, Siegel, and Lee (2008) present a similarity-based approach for estimating remaining useful life using data from a fleet composed of similar assets.

Umiliacchi, Lane, and Romano (2011) demonstrate the importance of having a standard format, especially for a fleet composed of similar asset types. Standardization of the diagnostic data is necessary to facilitate understanding across several subsystems and trains within a railway fleet. Zhang and Gockenbach (2008) present a methodology to use data acquisition derived from condition monitoring and standard diagnosis for asset management of transformers. They stress that standardization is required to develop multiple diagnostic models that combine results from tests and give an overall assessment of reliability and maintenance of transformers.

Based on review of fleet-wide diagnosis and prognosis architecture, the FW-PHM Suite definitely advances the state-of-the-art in fleet-wide prognostics and health management. The main contribution of this research is highlighted in following section.

\section{Fleet-Wide Prognostic and Health Management Suite SoftWare}

The FW-PHM Suite software is an integrated suite of webbased diagnostic and prognostic tools and databases, 
developed for EPRI by Expert Microsystems, specifically designed for use in the commercial power industry (for both nuclear and fossil fuel generating plants). The FW-PHM Suite serves as an integrated health management framework, managing the functionality needed for a complete implementation of diagnostics and prognostics (EPRI, 2012). The schematic in Figure 1 shows the four primary modules in the FW-PHM Suite: the Diagnostic Advisor, the Asset Fault Signature Database, the Remaining Life Advisor, and the RUL Database. The FW-PHM Suite has the capability to perform diagnosis and prognosis at different hierarchical levels, from the component level to the plant level, across a fleet of power units.

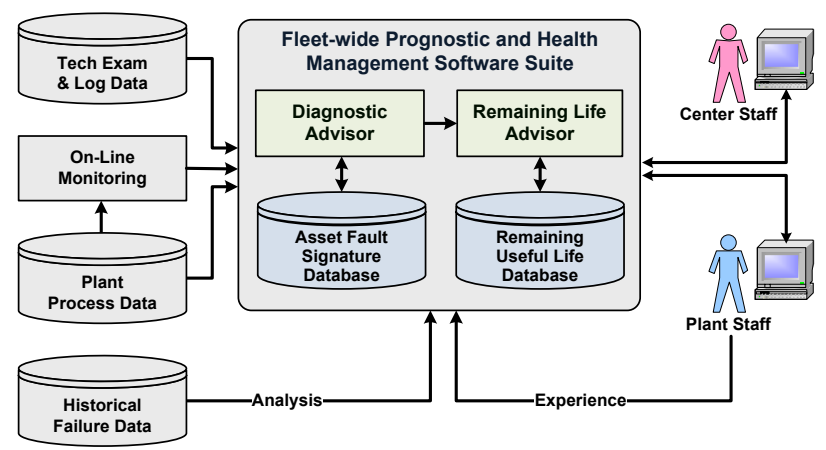

Figure 1. Data flow in the EPRI FW-PHM Suite (EPRI, 2012)

The current fleet-wide monitoring framework in the nuclear industry is based on feeding sensory data from a fleet asset into an advanced pattern recognition toolbox for anomaly detection. A pattern of anomalies is reviewed by an expert for recommendation. The FW-PHM Suite builds on the existing framework by automating the process of learning the pattern of anomalies (referred in this paper as fault signatures). The process of learning improves over time as new asset fault conditions and operating life information are discovered and cataloged by the Suite's users. The Advisor modules (discussed in this section) perform this learning automatically. These Advisors can acquire and process information from plant data historians, advanced pattern recognition, and other online monitoring tools. In addition, the Database modules, discussed in Sections 3.1 and 3.3, include information structures useful for nuclear generating station system technicians and component engineers. These structures contain information such as Institute of Nuclear Power Operations AP-913 process classifications; Maintenance Rule (10 CFR 50.65) designations, Performance Monitoring, and Corrective Action plan criteria; Maintenance Preventable Fault classifications; and Maintenance Preventable Functional Failure classifications. Cross references to other industry databases, such as the Generating Availability Data System and Equipment Performance and Information Exchange databases, are also provided. With these enhancements, the research presented in this paper advances the state-of-the-art in the area of fleet-wide prognostics and health management for the power industry.

\subsection{Asset Fault Signature Database}

The Asset Fault Signature (AFS) Database organizes fault signatures collected from the many EPRI member utilities. At the most basic level, fault signatures are comprised of an asset type, a fault type, and a set of one or more fault features (symptoms) that are indicative of the specified fault. Installation of the software at a plant or fleet monitoring center includes the master copies of the AFS and RUL databases, which are maintained and distributed by EPRI. A user at a plant or fleet monitoring center can develop additional fault signatures and RUL models in the AFS and RUL databases, respectively, thereby creating a local database based on user experience. The local databases can be exported and sent to EPRI periodically for evaluation and possible inclusion in the master database that is shared amongst EPRI members as shown in Figure 2. The process of developing fault signatures to populate the AFS Database is described in Agarwal, Lybeck, Matacia, and Pham (2013).

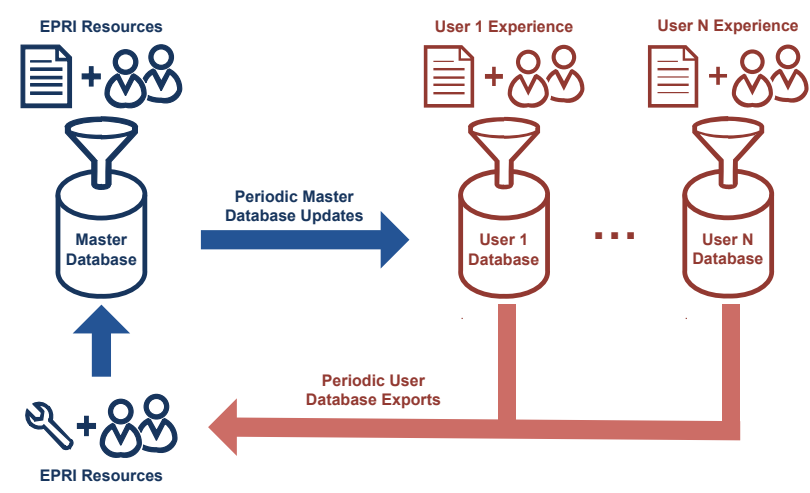

Figure 2. EPRI master database and user local database aggregation and periodic master database update

(EPRI, 2012)

\subsection{Diagnostic Advisor}

The Diagnostic Advisor identifies possible faults by comparing asset fault signatures with operating data using a rule-based approach. The Diagnostic Advisor is expected to be used on a daily or other periodic basis by technicians who are monitoring the health of a specific asset in the plant. Using either online data sources or information that is input manually (or a combination of online and offline data), the Diagnostic Advisor presents the most likely faults (if any) based on the available information, and, when appropriate, recommends additional information that might be used to discriminate amongst the possible faults. The Diagnostic Advisor is expected to streamline the diagnosis process by helping the technician focus his/her efforts on the 
most likely faults and possible causes based on the operating behavior of the system.

\subsection{Remaining Life Advisor}

Once a fault is indicated by the Diagnostic Advisor, plant personnel may wish to estimate the RUL of the asset. The Remaining Life Advisor calculates the RUL for an asset based on the model type, model parameters, input process parameters, and diagnostic information from the Diagnostic Advisor. The Remaining Life Advisor is expected to be used on a periodic basis by technicians who are monitoring the health of a specific asset in the plant.

Note that it is up to the user to decide which RUL model(s) are most appropriate for the circumstances. FW-PHM displays the results of all RUL estimates for the asset, but does not combine estimates from different models. The ability to implement user-defined models creates a flexible framework which could allow the development of specialized capabilities.

\subsection{Remaining Useful Life Database}

The RUL Database organizes asset RUL signatures (i.e., prognostic models) collected from across the industry. At the most basic level, a RUL signature is comprised of an asset type, a model type (e.g., reliability-based models, stressor-based models, or degradation-based models), and model calibration parameters. Type I: Reliability-based models include Weibull, exponential, and Gaussian distributions. Type II: Stressor-based models include Markov Chain and Proportional Hazard models. Type III: Degradation-based models include General Path models with Bayesian updating techniques. For more details on each model type, refer to Coble (2010). A RUL Signature also defines limiting conditions that characterize the end of life. The model type definition includes specification of the input variables needed to run the model. Subject matter experts from the power industry, EPRI, and EPRI's partners/subcontractors will most likely develop RUL signatures.

\section{Diagnostic Models (A.K.A. Fault Signatures)}

Both the AFS Database and the Diagnostic Advisor are required to first detect and then verify the occurrence of a specific type of fault. A fault is a particular mode of degradation that can be detected by analyzing plant information before the asset fails to meet its service requirement. Implied is an assumption that the fault is detectable by analysis of plant information and that the analysis can be performed in time to prevent or otherwise remedy the fault condition before it becomes a failure.

A methodical approach is adopted to develop content (i.e., fault signatures) for the AFS Database. Fault signatures are developed for application to a specific type of asset and are therefore organized with reference to that type of asset. However, it is desirable to specify fault signatures as broadly as possible to be used in the entire industry. The fault signatures defined in this research can be applied to comparable assets used in similar service environments (for example, assets like GSU, motors, pumps, found in power industries).

Some important terminologies associated with the AFS Database and fault signatures are explained with examples in following sections.

\subsection{AFS Database Terminologies}

The AFS Database contains tables that organize and store reference information for various power plant assets. This information can be represented using an asset subtype and a reference asset type hierarchy as shown in Figure 3. Asset types represent a more specific definition of an asset subtype, including information related to its use in service within a particular kind of plant or plant application. One example of an asset type is a bushing within the main transformer, shown in a screen shot from FW-PHM in Figure 3. Asset subtypes represent a generalized definition of an asset, without specifying contextual information such as the nature of its use in service within a particular kind of plant or the plant application. The draw-lead and fixedconductor bushings shown in Figure 4 are examples of asset subtypes at the component level.

Asset subtypes and asset types are organized into five discrete levels within the Signature Database: plant, unit, system, equipment, and component. Asset types are additionally organized within a set of reference asset hierarchies for various kinds of power generating plants. The collection of reference asset hierarchies is called the reference asset taxonomy. For details, refer to Agarwal, Lybeck, Bickford, and Rusaw (2014).

Fault types represent a specific definition of a fault, including contextual information such as its location and the nature of its use within a particular kind of power plant application. Fault information tables are used to organize and store information for the different fault types associated with plant assets. Paper insulation degradation in a transformer winding is an example of a fault type. Attributes associated with fault types can be used to tailor how the fault applies. Fault attributes and their values also provide a way to discriminate specific fault causes (e.g., arcing and cellulose degradation are two of the fault attributes associated with paper insulation degradation).

Technology examination tables organize and store information about technology examinations performed for various plant assets. Here, the term technology examination is not limited to instrumentation and measurement (vibration, temperature, oil, etc.) analysis, but is broadened to mean any form of examination of plant information, 
including operator examinations such as inspections, and even maintenance actions that can influence a fault diagnosis. An example would be an oil analysis that counts the number of particles found in a sampled volume of oil.

Technology subtypes represent the various technologies available to observe degradation indications. Examples of technology subtypes include vibration, oil analysis, and temperature. Exam subtypes represent the various exams associated with technology subtypes that can be performed to measure or observe the degradation indicators. Acid number is an exam subtype associated with oil analysis.

Result types define the possible set of outcomes for a technology examination. Each technology examination is associated with a single result type. The term exam result refers to the outcome of a technology examination. Exam results can be represented as categorical values or noncategorical values. Non-categorical values can include numeric values, a time series of numeric values, or a vector of numeric values.

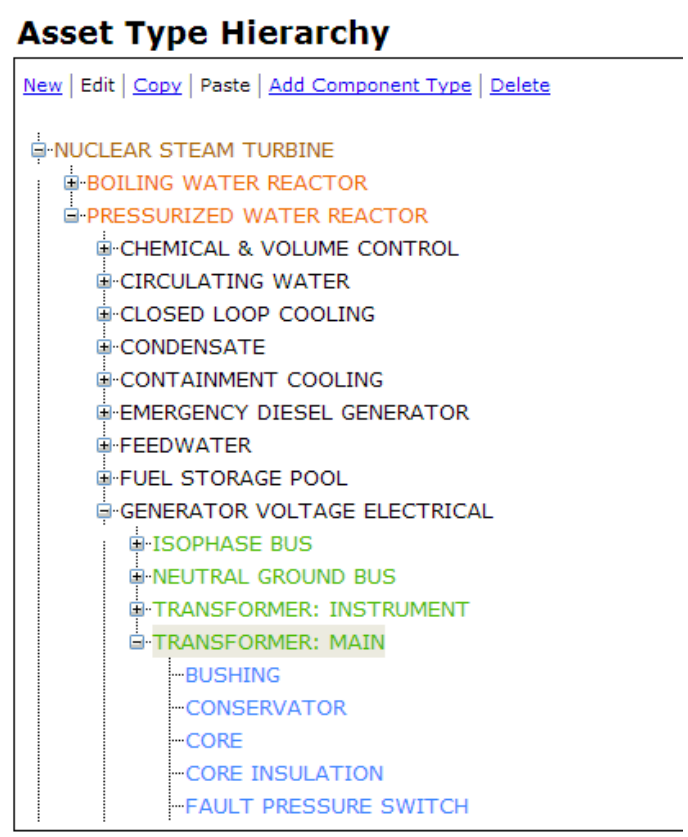

Figure 3. An example of asset types

\section{Component Subtypes}

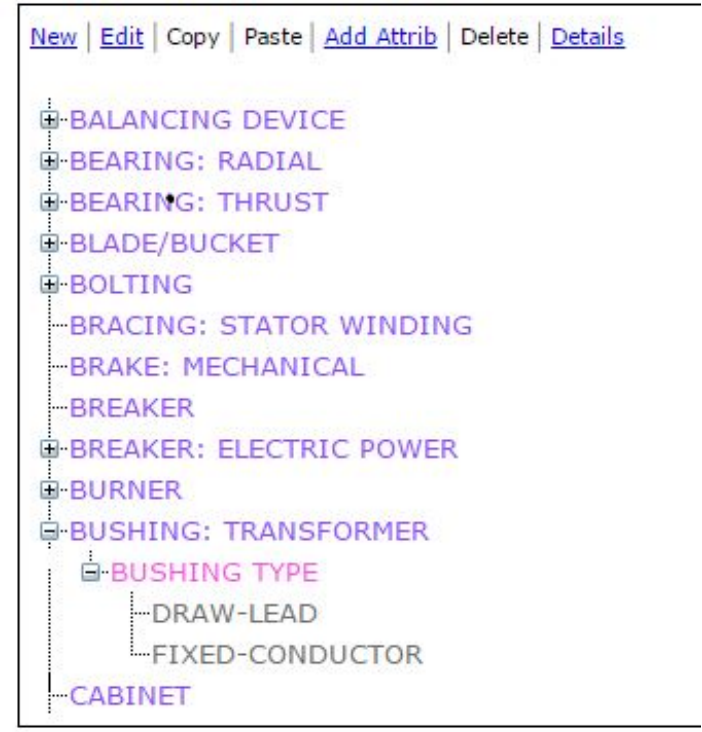

Figure 4. An example of asset subtypes at the component level

\subsection{Asset Fault Signatures}

Asset fault signature tables, the backbone of the AFS Database, are used to organize diagnostic fault signature information. At a minimum, a fault signature is comprised of an asset type, a fault type and a set of one or more observable features that may indicate the presence of the associated fault. Optionally, the fault signature can specify one or more fault types that can either cause or be caused by the specified fault. Corrective actions or a list of possible remedies can also be included in a fault signature.

Fault feature tables organize and store information for the fault features associated with various fault signatures. A fault feature definition includes a technology examination type, the location for the technology examination, and the fault values. Fault values are the categorical classifications of examination results, such as those output by an advanced pattern recognition system, that indicate the possible presence of the specified fault. Additionally, a fault feature describes the effectiveness of the associated technology examination. Effectiveness is used in ranking possible diagnosis of the Diagnostic Advisor, especially in a situation where the same technical examination is used to diagnose different fault types.

For example, a high-temperature measurement is a highly effective fault feature for a bearing damage fault in a pump. Figure 5 shows the fault signature representing insulating oil degradation due to contamination, including associated fault features, implemented in the AFS Database of the FW-PHM Suite. The complete list of fault signatures associated with the insulating oil degradation is seen in the upper-left corner of Figure 5. The fault values listed include change, 


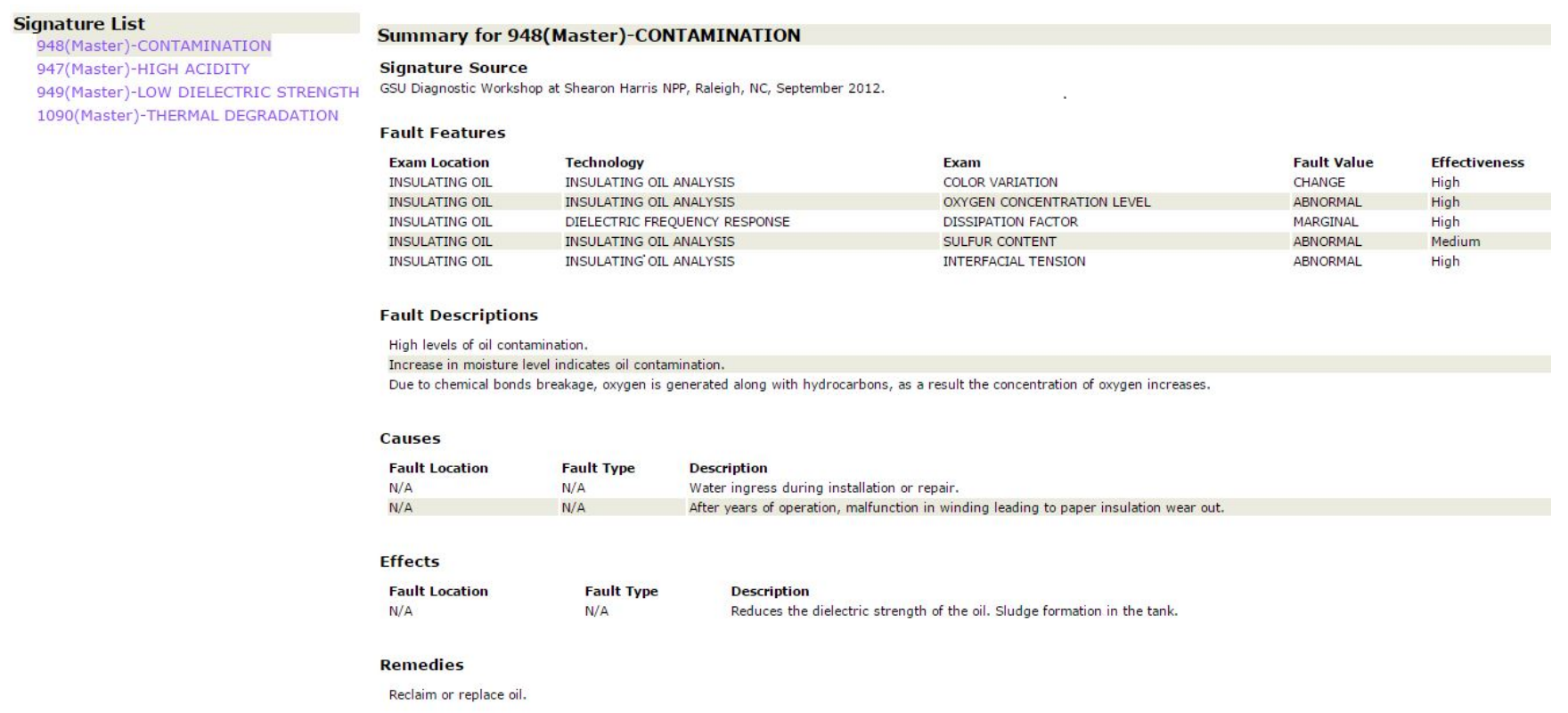

Figure 5. Insulating oil degradation due to contamination and associated fault features

indicating an identifiable change from the baseline state (in this case, a change in color); abnormal, indicating the examination result is outside the expected range; and marginal, which is the middle fault value in a graduated assessment (normal, watch list, marginal, unacceptable).

\subsection{Gathering Fault Signatures Information}

A step-by-step procedure for developing a fault signature includes the following four steps (EPRI, 2012):

- $\quad$ Specify the asset type for which the fault signature(s) is to be developed. For the specified asset type, gather information on its normal operating range, mechanisms of degradation, and observable features that can be used to detect degrading conditions. This information can be gathered from multiple sources such as EPRI's Preventive Maintenance Basis Database, the Fossil Maintenance Application Center and the Nuclear Maintenance Application Center, and from other sources (e.g., textbooks, equipment guide, and publications). Specify the fault type and any narrowing attributes that can be used to make the fault more specific. For instance, the most common fault type associated with transformer winding is paper insulation degradation. Fault attributes such as arcing, cellulose decomposition, high oil acidity, high oil moisture level, and partial discharge are commonly used to identify the root cause of paper insulation degradation in a transformer winding.

- For each fault type, specify one or more fault features comprised of information on (1) location where the plant data are collected; (2) technology or technologies used to identify the fault (e.g., oil analysis in transformers); (3) examination (e.g., particle content, dissolved gas analysis or moisture content) and outcome of examination (i.e., the result, whether normal, abnormal, high marginal, or unacceptable); and (4) the effectiveness (e.g., low, medium, high, or very high) of the fault feature in detecting the fault condition. A specific fault type can be associated with one or more fault signatures based on one or more fault features.

- Provide a description of the fault condition, possible causes, remedies, and effects on the asset (if left uncorrected).

Several fault signatures have been developed and implemented in the AFS Database as part of a knowledge transfer exercise with utility partners for GSUs (Agarwal, Lybeck, Pham, Rusaw, and Bickford [2013] and Lybeck, Agarwal, Pham, Medema, and Fitzgerald [2012]) and for emergency diesel generators (Pham et al. [2012] and Agarwal et al. [2013]). Twenty-two fault signatures have been implemented in the AFS Database for GSUs. The list of implemented fault signatures for GSUs is summarized in Appendix B of Agarwal, Lybeck, and Pham (2014). Independent subject matter experts from EPRI validated all the fault signatures for GSUs.

Based on the implemented fault signatures for GSUs in the AFS Database, a diagnostic exercise was performed to evaluate the diagnostic capability of the FW-PHM Suite using simulated fault data.

\section{Diagnosis Process}

The ability of the Diagnostic Advisor to diagnose possible faults was evaluated by comparing known asset fault 
signatures with operating data. For evaluation purposes, dissolved gas analysis (DGA) data with simulated faults were utilized. In this paper, a synopsis of the diagnostic exercise based on DGA of transformer insulation oil is presented. A detailed diagnostic exercise is documented in a report by Agarwal, et al. (2013) and in a YouTube video (2013).

\subsection{Simulated DGA Data}

DGA is a commonly used technical examination that is performed to diagnose thermal or electrical faults occurring inside an operating transformer. Thermal or electrical faults decompose hydrocarbon bonds, resulting in generation of gases within the transformer. One of the most important aspects of oil analysis is to measure the concentration of key dissolved gases. The key gases include hydrogen $\left(\mathrm{H}_{2}\right)$, methane $\left(\mathrm{CH}_{4}\right)$, acetylene $\left(\mathrm{C}_{2} \mathrm{H}_{2}\right)$, ethylene $\left(\mathrm{C}_{2} \mathrm{H}_{4}\right)$, and ethane $\left(\mathrm{C}_{2} \mathrm{H}_{6}\right)$. In addition to the key gases, carbon monoxide $(\mathrm{CO})$, carbon dioxide $\left(\mathrm{CO}_{2}\right)$, oxygen $\left(\mathrm{O}_{2}\right)$, and nitrogen $\left(\mathrm{N}_{2}\right)$ are also generated, even under normal operating conditions. The gas ratios such as $\mathrm{O}_{2} / \mathrm{N}_{2}, \mathrm{CO}_{2} / \mathrm{CO}$, $\mathrm{C}_{2} \mathrm{H}_{2} / \mathrm{H}_{2}$, Doernenberg Ratios (IEEE, 2008), Duval triangle (Duval, 2002), and Rogers Ratios (IEEE, 2008) indicate different types of degradation inside transformers.

A dissolved gas concentration data set collected between April 2012 and April 2013 from a NPP was used to evaluate the FW-PHM's diagnostic capability. The data also includes top insulating oil temperature, water concentration level in insulating oil, and fan and motor amperage for the transformer cooling system. A positive drift was introduced in both the $\mathrm{C}_{2} \mathrm{H}_{2}$ and $\mathrm{CO}$ concentration levels to simulate primary winding insulation degradation, a common failure mode in GSU. As a result of the increase in the $\mathrm{CO}$ concentration level, a decrease in the $\mathrm{CO}_{2} / \mathrm{CO}$ ratio is observed. The introduction of the drift in the actual data was performed using commercially available advanced pattern recognition software.

The gas concentration data with drift reflect 3 out of 4 classification criteria (Condition 1 through Condition 3) developed by the Institute of Electrical and Electronics Engineers (IEEE) to classify risk to transformers. Table 1 lists the dissolved gas concentrations for the individual gases for Condition 1 through Condition 4. Table 1 is used to make an initial assessment of a gassing condition on a new or recently repaired transformer if there are no previous tests on the transformer for dissolved gases or if there is no recent history available. For details on Condition 1 through Condition 4, refer to IEEE (2008). Condition 1, Condition 2, and Condition 3 in Table 1 for individual gas concentrations are mapped to Normal, Watch List, and Marginal, respectively, in the FW-PHM Suite. Condition 4 is mapped to Unacceptable in the FW-PHM Suite. For details on how mapping is performed, refer to Agarwal et al. (2013).

\begin{tabular}{|c|c|c|c|c|c|c|c|c|}
\hline \multicolumn{9}{|c|}{ Dissolved key gas concentration limits $[\mu L / L(p p m)]$} \\
\hline Status & $\begin{array}{l}\text { Hydrogen } \\
\left(\boldsymbol{H}_{2}\right)\end{array}$ & $\begin{array}{l}\text { Methane } \\
\left(\mathrm{CH}_{2}\right)\end{array}$ & $\begin{array}{l}\text { Acetylene } \\
\left(\boldsymbol{C}_{2} \mathrm{H}_{2}\right)\end{array}$ & $\begin{array}{l}\text { Ethylene } \\
\left(C_{2} H_{4}\right)\end{array}$ & $\begin{array}{l}\text { Ethane } \\
\left(C_{2} H_{6}\right)\end{array}$ & $\begin{array}{l}\text { Carbon } \\
\text { monoxide } \\
(\mathrm{CO})\end{array}$ & $\begin{array}{l}\text { Carbon } \\
\text { dioxide } \\
\left(\mathrm{CO}_{2}\right)\end{array}$ & $T D C G$ \\
\hline Condition 1 & 100 & 120 & 1 & 50 & 65 & 350 & 2500 & 720 \\
\hline Condition 2 & $101-700$ & $121-400$ & $2-9$ & $50-100$ & $66-100$ & $351-570$ & $2500-4000$ & $721-$ \\
\hline Condition 3 & $701-1800$ & $\begin{array}{l}401- \\
1000 \\
\end{array}$ & $10-35$ & $101-200$ & $101-150$ & $571-1400$ & $4001-10000$ & $1921-4630$ \\
\hline Condition 4 & $>1800$ & $>1000$ & $>35$ & $>200$ & $>150$ & $>1400$ & $>10000$ & $>4630$ \\
\hline $\begin{array}{l}\text { Note: TDCQ } \\
\text { Condition 1: } \\
\text { exceeding sp } \\
\text { Condition 2: } \\
\text { gas exceedin } \\
\text { Condition } 3 \text { : } \\
\text { the specified } \\
\text { Condition } 4 \text { : } \\
\text { the transform }\end{array}$ & $\begin{array}{l}\text { stands for tot } \\
\text { TDCG below } \\
\text { cified levels } \\
\text { TDCG withi } \\
\text { the specifiec } \\
\text { TDCG withir } \\
\text { level should } \\
\text { TDCG excee } \\
\text { er. }\end{array}$ & $\begin{array}{l}\text { al dissolved } \\
\text { this level } i \\
\text { should pron } \\
\text { this range } \\
\text { level shou } \\
\text { this range } \\
\text { rompt addi } \\
\text { ding this va }\end{array}$ & $\begin{array}{l}\text { combustible } \\
\text { dicates the } \mathrm{t} \\
\text { pt additional } \\
\text { indicates gre } \\
\text { l prompt add } \\
\text { ndicates a hi } \\
\text { onal investig } \\
\text { le indicates }\end{array}$ & $\begin{array}{l}\text { as volume. } \\
\text { insformer } \\
\text { investigatio } \\
\text { ater than no } \\
\text { tional inves } \\
\text { sh level of } \\
\text { ation. } \\
\text { xcessive de }\end{array}$ & $\begin{array}{l}\text { operating } \\
\text { mal combi } \\
\text { gation. } \\
\text { ecompositi } \\
\text { mposition }\end{array}$ & $\begin{array}{l}\text { tisfactorily. } \\
\text { ible gas leve } \\
\text { Any indivic } \\
\text { Continued op }\end{array}$ & $\begin{array}{l}\text { y individual cc } \\
\text { Any individu } \\
\text { al combustible } \\
\text { tion could rest }\end{array}$ & $\begin{array}{l}\text { mbustible gas } \\
\text { l combustible } \\
\text { gas exceeding } \\
\text { lt in failure of }\end{array}$ \\
\hline
\end{tabular}

Table 1. Dissolved gas concentrations (IEEE, 2008) 


\subsection{Information Communication Pathway}

The commercially available advanced pattern recognition software used in this research writes the simulation output to an Oracle 11g Database. The Diagnostic Advisor in the FW-PHM Suite is configured to read information from the database, thereby creating a communication pathway. The Diagnostic Advisor of the FW-PHM Suite utilizes the communication pathway to periodically update its online data query and perform diagnoses. The update interval is user-defined and can range from every minute to every month. If the updated information identifies any potential fault, the Diagnostic Advisor generates a new diagnosis result and sends an e-mail notification to the designated person.

\subsection{Diagnostic Advisor Diagnosis}

The Diagnostic Advisor of the FW-PHM Suite takes advantage of the communication pathway to diagnose primary winding insulation degradation based on simulated primary winding fault data. For performance evaluation, gas concentration levels and gas ratios are played back at an accelerated pace and monitored continuously. In practice, changes in gas concentration and gas ratios are slow and might take several months to reach the Warning stage. The scenario presented in this paper was developed specifically to demonstrate the diagnostic capability of the FW-PHM Suite and should not be misconstrued as a real-world situation.

Paper insulation degradation due to electrical discharge leads to either the occurrence of a partial discharge phenomenon or an arcing phenomenon. A steep increase in the $\mathrm{H}_{2}$ concentration level compared to other dissolved gases in the transformer insulating oil is an indication of partial discharge. Similarly, an increase in the combined $\mathrm{H}_{2}$ and $\mathrm{C}_{2} \mathrm{H}_{2}$ concentration levels compared to other dissolved gases is an indication of arcing. Electrical discharge can create localized hotspots, causing an increase in the top insulating oil temperature.

Paper insulation degradation due to thermal phenomena can be diagnosed when a steep increase in the $\mathrm{CO}$ concentration level is observed. The rate of increase of $\mathrm{CO}$ and $\mathrm{CO}_{2}$ are different, so a decrease in the $\mathrm{CO}_{2} / \mathrm{CO}$ ratio also indicates thermal degradation of primary winding paper insulation.

In the example presented in this paper, the diagnosis process begins with monitoring $\mathrm{C}_{2} \mathrm{H}_{2}$ and $\mathrm{CO}$ concentration levels, as well as the $\mathrm{CO}_{2} / \mathrm{CO}$ ratio. As long as the monitored gases are within normal range, no new diagnoses are observed in the FW-PHM Suite. As the monitoring continues, the $\mathrm{C}_{2} \mathrm{H}_{2}$ concentration level indicator reaches the warning level, equivalent to IEEE Condition 2 (Watch List in FW-PHM).

This information is continuously logged into the Oracle Database. The Diagnostic Advisor of the FW-PHM Suite, via the information communication pathway, reads the updated information from the Oracle Database. At this point, the Diagnostic Advisor immediately recognizes the change in the $\mathrm{C}_{2} \mathrm{H}_{2}$ concentration level and creates a new diagnosis, as seen in Figure 6.

The Diagnosis Result Page has several different information sections. The Possible Diagnosis section displays the latest diagnosis results with information on Fault Location, Possible Diagnosis, Pattern Score, Likelihood Score, Details, Status, Broad Search Used, AP-913 Condition Code, and Exact Match. Fault Location communicates the location of the fault; in this case, it says Primary Winding Insulation (as expected). Possible diagnosis identifies the most likely fault based on the current available information.

In this case, Paper Insulation Degradation: Electrical is identified as the most likely diagnosis based on the current $\mathrm{C}_{2} \mathrm{H}_{2}$ concentration level (as expected). The pattern score is a percentage indicating the relative likelihood of the fault based on the current information. The pattern scores always sum to $100 \%$. Note that the Exact Match column denotes how many fault features in the signature are exactly matched; partial matches (e.g., a watch list result when the fault value is defined to be marginal) are given less weight in the Pattern Score, and are not counted as exact matches.

The Result History section lists all the diagnoses performed by the Diagnostic Advisor. The Query Values section lists query values for the mapped technology. In this case, observe that the query values for all the exams are normal except for $\mathrm{C}_{2} \mathrm{H}_{2}$, which reads Watch List. The Troubleshooting Advice section lists other fault features that could be mapped to the Oracle Database or could be entered manually, to further refine the diagnosis result. In this case, the suggested troubleshooting advice is to analyze the Acid Number of the insulating oil.

As monitoring continues, the $\mathrm{C}_{2} \mathrm{H}_{2}$ concentration level continues to increase and is allowed to reach IEEE Condition 4 (i.e., Unacceptable). After a short time interval of monitoring, the $\mathrm{CO}$ concentration level indicator reached IEEE Condition 2 (i.e., Watch List). The new information is updated in the Oracle Database. The Diagnostic Advisor reads the updated information, updates the previous diagnoses result based on new information, and sends a new e-mail notification. 


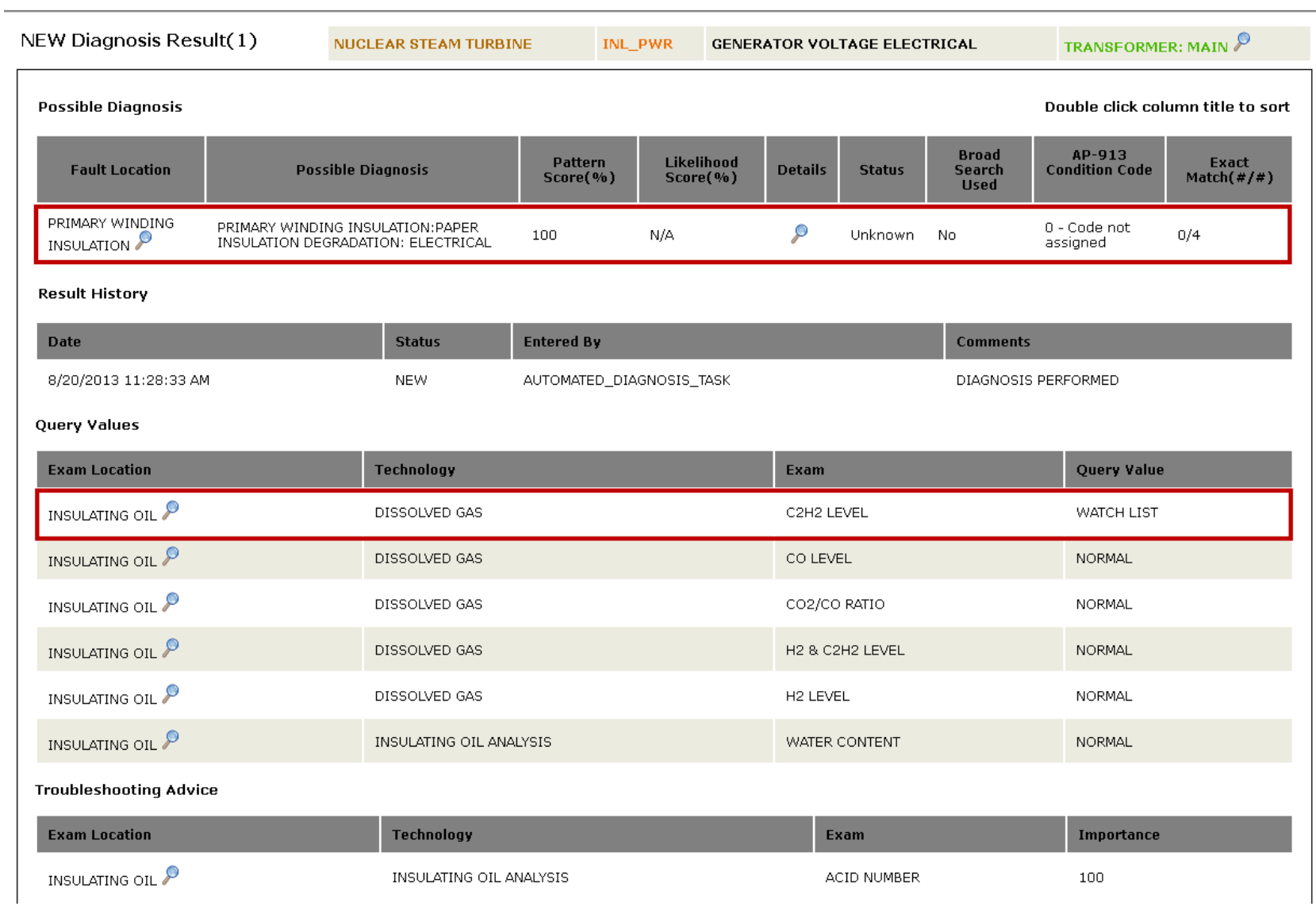

Figure 6. New diagnosis result summary page created by the Diagnostic Advisor when $\mathrm{C}_{2} \mathrm{H}_{2}$ level reaches Watch List

As monitoring continues, the FW-PHM's Diagnostic Advisor polls the Oracle Database at regular intervals to generate a series of diagnoses as shown in Figure 7. For the example presented in this paper, the Diagnostic Advisor polled the Oracle Database every minute. Observe that the updated Diagnosis Result Page presents the diagnosis update history and updated possible diagnosis with current query values. With time, Possible Diagnosis has been updated and now Paper Insulation Degradation: Thermal is identified as the most likely diagnosis based on the current $\mathrm{C}_{2} \mathrm{H}_{2}, \mathrm{CO}$, and $\mathrm{CO}_{2} / \mathrm{CO}$ ratio. Also, observe that the Diagnostic Advisor has updated the Troubleshooting Advice, suggesting the inclusion of top insulating oil temperature information if possible (i.e., Time at Excess Temperature) to further refine the diagnosis.
This exercise demonstrated the Diagnostic Advisor's ability to

1. Capture the changes in the mapped fault features on an automated basis and update the corresponding diagnosis

2. Maintain diagnosis history

3. Provide troubleshooting advice that, if used, could assist the person in charge to differentiate between different possible diagnoses.

The exercise leverages the capability to connect the FWPHM Suite to a plant monitoring system, poll the data every minute, and perform an automated diagnosis based on current information.

A similar exercise was performed for emergency diesel generators, and the diagnostic outcome was consistent. Additional details are available in Agarwal et al. (2013). 


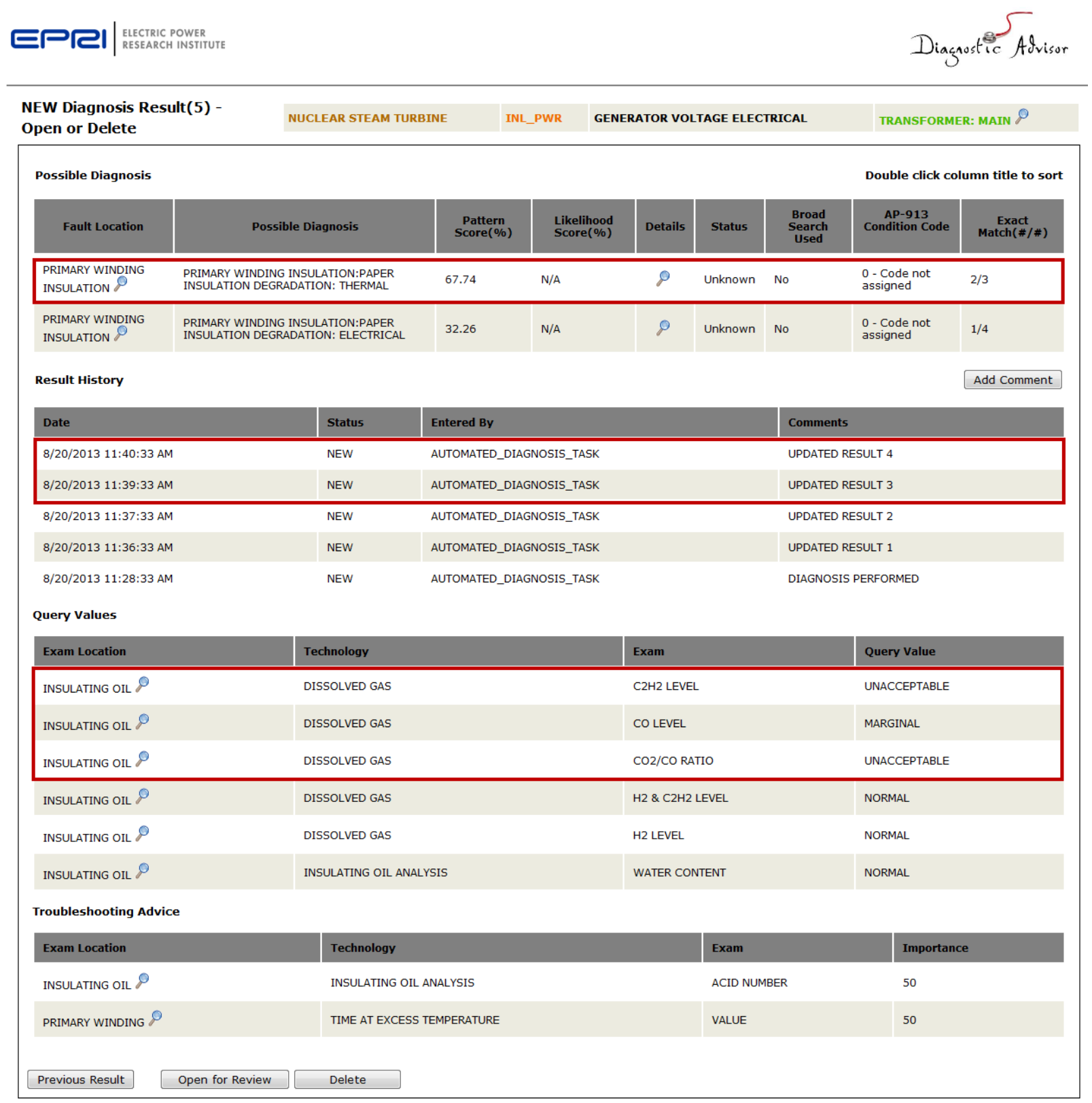

Figure 7. Updated new diagnosis result page indicating paper insulation degradation: thermal as the most likely fault

\section{Prognostic Models}

In addition to diagnosis, providing a risk-informed RUL estimate would enable a plant maintenance engineer to prioritize maintenance activities. Here risk-informed RUL estimation refers to the prioritization of the failure modes according to their consequence to the asset. A user can enter both probability of failure and the consequence index for each failure mode into the FW-PHM suite based on history of failure or experience. This would allow the user to optimize the maintenance strategy to reduce the risk. This capability would fill the gap between the need for timely, accurate performance analysis and the availability of plant engineering resources. The engineering focus could be shifted from identifying potential problems, diagnosing asset failures, and providing maintenance guidance to actually solving the problem. Valuable operating assets could avoid premature or untimely failure, or avoid lifelimiting modes of operation.

The prognostic models discussed in this paper are used to estimate the RUL of power transformer conductor windings. High-voltage power transformer conductor windings are insulated by a combination of cellulose paper and an insulating mineral oil, and are expected to operate reliably for up to 40 years. Cellulose is a natural polymer of glucose 
that degrades slowly as the polymer chains break down during service, releasing chemical by-products that dissolve in the insulating oil. The factors and mechanisms that contribute to transformer winding insulation paper degradation are well studied in the literature, including cellulose reaction (Cheim, Platts, Prevost, and Xu, 2012), degradation due to hydrolysis (Hohlein and Kachler, 2005), and thermolysis (Lundgaard, Hansen, and Ingebrigtsen, 2008). Transformer winding paper insulation degradation rate is critical in determining the operational life span of a transformer. The actual state of the insulation in the transformer can only be determined by a tear-down inspection. However, the state of the insulation can be inferred from knowledge of parameters or stressors correlated with insulation degradation.

Therefore, this paper presents two prognostic models for transformer paper winding insulation degradation that were researched and implemented in the FW-PHM Suite. The Chendong (1991) model estimates degree of polymerization (DP) of the transformer winding insulation based on the concentration level of 2 Furaldehyde (2FAL), measured by offline oil analysis. The IEEE thermal life consumption model (IEEE, 2012) estimates the hot spot temperature in the insulation at a given transformer load and ambient temperature.

Both of the models were implemented in the RUL Database of the FW-PHM Suite. The Remaining Life Advisor evokes the implemented prognostic models to estimate the RUL of transformer paper winding insulation based on the DP or history of hot spot temperature.

\subsection{Chendong Model}

DP has traditionally been used as the primary indicator of the condition of insulation paper in transformers. The paper insulation deteriorates with age due to stresses generated by thermal, mechanical, and electrical transients. A lowering of the DP corresponds to scission of cellulose chains, a chemical breakdown reaction reducing the mechanical strength of the paper. When the DP falls below approximately 250 , the paper is weak and brittle (fresh paper has a DP of 1100-1200). Although examples of paper insulation with DP values as low as 150 have been found in operating transformers (Emsley and Stevens, 1994), DP values around 250 are generally considered to indicate imminent failure. Experimental studies suggest that the DP value varies along the length of the transformer winding. Therefore, it is important to consider an average DP value over the length of the transformer winding (Emsley and Stevens, 1994).

Use of DP for accurate life prediction requires that the rate of degradation be properly calibrated, accounting for type of paper, operating temperature (the rate of degradation increases with temperature), and moisture. In addition, a nonlinear functional relationship exists between tensile strength and DP. Despite these limiting factors, DP is commonly used to estimate insulation age. DP of transformer insulation can be inferred by non-intrusively measuring the concentration of dissolved by-products such as furanic compounds in the insulating oil. 2FAL is the most predominant of the five furanic compounds that are generated due to cellulose paper aging (Emsley, Xiao, Heywood, and Ali, 2000). The relationship between 2FAL and DP is seen in Figure 8. Observe in Figure 8 that initially the DP value decreases as $2 \mathrm{FAL}$ concentration increases. Around 3000 hours, the concentration of 2FAL starts to decrease. This illustrates that the relationship between DP and 2FAL is not monotonic. In addition if the transformer insulation oil is reclaimed it would impact the $2 \mathrm{FAL}$ concentration but would not affect the DP value, which is as expected. For further discussion on furanic compounds and other oil-soluble decomposition products, refer to Agarwal et al. (2014).

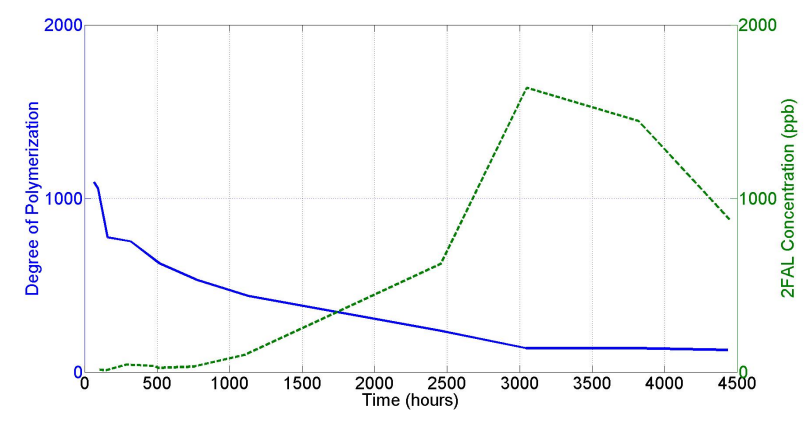

Figure 8. A functional relationship between $2 \mathrm{FAL}$ concentration in oil (dashed) and degree of polymerization (solid) over time

Several mathematical models have been developed based on the observed relationship between DP value and the $2 \mathrm{FAL}$ concentration. One of the most widely used models is the Chendong model (1991) given in Eq. (1), which is based on a series of data collected from transformers with normal Kraft insulation paper and a free-breathing conservator.

The Chendong model exploits the release of furanic compound, estimating DP based on 2FAL, and then predicting remaining useful life. To establish the relationship between 2FAL content and DP, Chendong performed a regression analysis on the collected data as follows:

$$
\log (2 F A L)=1.51-0.0035 D P
$$

The data support a linear dependence between the DP value and the logarithm of the 2FAL concentration level. The DP of insulating paper directly reflects the transformer insulation condition, as shown in Table 2. Although the measurement of 2FAL concentration level from an oil sample is relatively simple, the differentiation of aging mechanisms affecting the formation of 2FAL compounds in 
the oil is complex. Nevertheless, Eq. (1) can be applied to approximate the average DP of insulating paper and estimate the aging level for the transformer insulation winding.

\begin{tabular}{l|l|l}
\hline $\begin{array}{l}\text { 2FAL } \\
\text { (ppm) }\end{array}$ & DP Value & Significance \\
\hline $0-0.1$ & $1200-700$ & Healthy insulation \\
\hline $0.1-1.0$ & $700-450$ & Moderate deterioration \\
\hline $1-10$ & $450-250$ & Extensive deterioration \\
\hline$>10$ & $<250$ & End-of-life criteria \\
\hline
\end{tabular}

Table 2. DP and 2FAL correlation (Aba-Siada, 2011)

A functional relationship between operating time and $2 \mathrm{FAL}$ concentration was established based on varying operating conditions of 77 step-up generator transformers (Chendong, 1991), along with confidence bounds. The confidence intervals are a function of operating time $(T)$ and are expressed as:

$$
\begin{aligned}
& \log \left(2 F A L_{1}\right)=-1.29+0.058 T \\
& \log \left(2 F A L_{2}\right)=-2.37+0.058 T
\end{aligned}
$$

Given the DP estimate from Eq. (1), the empirical formulation in Eq. (4) can be used to calculate the elapsed insulation life of a transformer:

$$
\text { Elapsed life (in years) }=20.5 \cdot \frac{D P_{t}}{D P_{0}}
$$

where $D P_{0}$ is the degree of polymerization of a new (un-aged) transformer and $D P_{t}$ is the degree of polymerization of the transformer at time $t$. In Eq. (4), the value 20.5 is the required minimum normal insulation life expectancy of 180,000 hours $(\sim 20.55$ years $)$ as per IEEE (2012).

\subsection{IEEE Thermal Life Consumption Model}

The IEEE thermal life consumption model presented here has been developed for mineral-oil-immersed transformers and step-voltage regulators with insulation systems rated for a $65^{\circ} \mathrm{C}$ average winding temperature rise at rated load. A transformer's life span is determined mainly by the solid insulation system's mechanical resistance to withstand a short circuit. As a result, the transformer life is usually defined as the total time between the initial state with new insulation and the final state for which dielectric stress, short circuit stress, or mechanical movement could cause an electrical failure (likely a short circuit) for a given temperature of the transformer insulation.

The IEEE thermal life consumption model estimates the hot spot temperature in the insulation at a given transformer load and ambient temperature, which in turn is used to estimate the transformer insulation life spent (or equivalent RUL).
IEEE (2012) presents two different models for calculation of hot spot temperatures. The model implemented here is a simplified model that calculates oil and winding temperatures for changes in load relative to the rated load. The alternate method is more exact, but requires an iterative solution of equations. If load, ambient temperature, and tap position can be determined accurately, the alternate method should provide more accurate results. Details can be found in (IEEE, 2012).

The hot spot temperature $\left(T_{H}\right)$ is given by:

$$
T_{H}=T_{A}+\Delta T_{T O}+\Delta T_{H / T O}
$$

where $T_{A}$ is the ambient temperature, $\Delta T_{T O}$ is the top oil temperature rise over ambient, and $\Delta T_{H / T O}$ is the hot spot temperature rise over top oil. Given the ambient temperature and load, the two remaining terms of the hot-spot temperature are calculated per the procedure and equations described in IEEE (2012).

The transformer insulation RUL can be calculated as:

$$
R U L=\text { Normal insulation life }-F_{E Q A} \times t
$$

where

$$
F_{E Q A}=\frac{\sum_{n=1}^{N} F_{A A, n} \Delta t_{n}}{\sum_{n=1}^{N} \Delta t_{n}}
$$

is the equivalent aging factor at the reference hot-spot temperature in a given time period with varying load profile. Here $F_{A A}$ is the aging acceleration factor for a given load resulting in corresponding hot spot temperature. The expression for $F_{A A}$ is

$$
\mathrm{F}_{A A}=e^{\left[\frac{15000}{383}-\frac{15000}{T_{H}+273}\right]}
$$

By substituting the $T_{H}$ in Eq. (5) into Eq. (7), the transformer insulation RUL can be calculated using Eq. (6).

\section{Prognostic Process}

In this section, the implementation of two Type II prognostic models in the Remaining Life Database and prognostic capability of the FW-PHM Suite using the RUL Advisor to estimate the GSU winding insulation lifetime are presented.

\subsection{Implementation of Prognostic Models in the FW- PHM Suite}

The procedure for implementing new prognostic models in FW-PHM is detailed in EPRI (2012). The implementation of each model in FW-PHM includes the following steps: programming the model and publishing it as a service; adding the model type to FW-PHM; defining the technical examinations required as model inputs; and creating a RUL signature for the asset in question, including parameter 
values. The RUL Advisor can then be used to estimate RUL.

The RUL signature associated with the Chendong model was implemented at a component level for the main transformer primary winding insulation. The model uses two calibration parameters, one for the minimum life expectancy of transformer winding insulation (in years) and the second for the initial DP when the transformer was placed in service. The single input to the model is the measured 2FAL concentration in ppm (parts-per-million).

The RUL signature associated with the IEEE Life Consumption model was also implemented at a component level for the main transformer primary winding insulation. The model uses nine calibration parameters, and requires one single input value and two time-series input values for load and ambient temperature.

For details on the implementation of the Chendong and IEEE thermal models in the FW-PHM Suite, refer Agarwal et al. (2014).

\subsection{RUL Estimation}

Test scenarios were developed to evaluate the performance and robustness of the implemented models in the FWPHM's RUL Database. A synopsis of the prognostic capability of the FW-PHM Suite using the RUL Database and Remaining Life Advisor is presented in this paper. The report by Agarwal et al. (2014) documents the detailed prognosis exercise.

For the Chendong model, a 2FAL concentration of $0.6 \mathrm{ppm}$ and an initial $D P_{0}=1150$ were assumed. Using Eq. (1), the estimated DP was 494.8, resulting in an elapsed life estimate of 17.3 years (Eq. [4]). The mean RUL estimate is 3.2 years given a life expectancy of 20.5 years. FW-PHM has the capability to display upper and lower bounds for RUL. The best way to calculate uncertainty for the Chendong model is a topic for future research. For the purposes of evaluation, the upper and lower bounds on RUL were calculated simply as 1.05 and 0.95 times the average RUL, respectively. For more information, refer to Agarwal, Lybeck, Pham, Bickford, and Rusaw (2015).

For the IEEE thermal model, a data set was fabricated using average ambient temperature from Idaho Falls, Idaho between June 1, 2013, and August 1, 2014. The load and ambient temperature profiles are shown in Figure 9. The left (solid) axis is the ratio of measured load to rated load, and the right (dashed) axis is ambient temperature. The model input parameters are described in Table 3. The transformer was assumed to have previous usage of 17.2 years.

Figure 10 shows the RUL estimate based on these data in the PHM prognostic advisor. The load ratios are generally a higher than rated load for this data set, thus the usage estimate shows 1.35 years of life were consumed during this 1-year period. The mean RUL estimate is given by the expected insulation life minus the sum of the life spent (the input usage value of 17.2 years) and the estimated usage: $20.5-(17.2+1.35)=1.95$ years. Again, in this case, the upper and lower bounds on RUL are simply calculated to be 1.05 and 0.95 times the mean RUL.

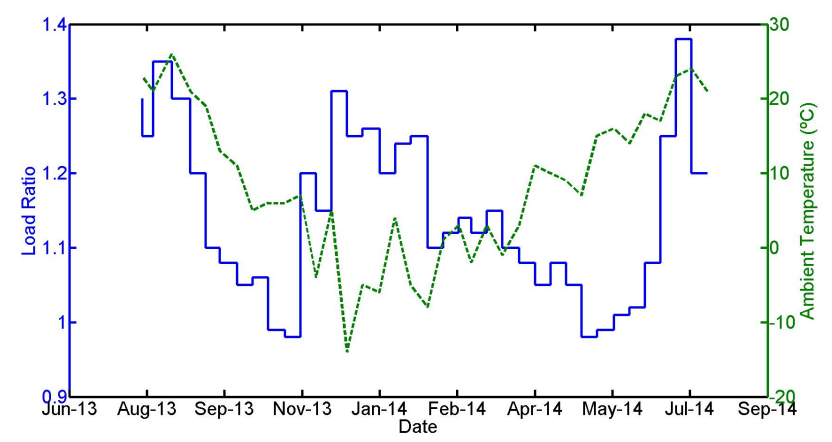

Figure 9. Load (solid) and ambient temperature (dashed) profile

\begin{tabular}{|c|c|c|}
\hline Parameter Name & $\begin{array}{l}\text { Parameter } \\
\text { Value } \\
\text { (Unit) }\end{array}$ & Description \\
\hline $\mathrm{R}$ & 4.87 & $\begin{array}{l}\text { Ratio of load loss at } \\
\text { rated load to no-load } \\
\text { loss }\end{array}$ \\
\hline $\mathrm{dT}_{-} \mathrm{TOR}$ & $36.0^{\circ} \mathrm{C}$ & $\begin{array}{l}\text { Top oil temperature } \\
\text { rise over ambient at } \\
\text { rated load }\left({ }^{\circ} \mathrm{C}\right)\end{array}$ \\
\hline dT_HSTOR & $28.6^{\circ} \mathrm{C}$ & $\begin{array}{l}\text { Winding hot spot } \\
\text { temperature rise over } \\
\text { top oil temperature at } \\
\text { rated load }\left({ }^{\circ} \mathrm{C}\right)\end{array}$ \\
\hline dT_HSAR & $80^{\circ} \mathrm{C}$ & $\begin{array}{l}\text { Winding hot spot rise } \\
\text { over ambient at rated } \\
\text { load }\left({ }^{\circ} \mathrm{C}\right)\end{array}$ \\
\hline $\mathrm{T}_{-} \mathrm{TOR}$ & $3.5 \mathrm{~h}$ & $\begin{array}{l}\text { Oil thermal time } \\
\text { constant for rated } \\
\text { load (hours) }\end{array}$ \\
\hline $\mathrm{T}_{-} \mathrm{W}$ & 0.083 & $\begin{array}{l}\text { Winding time } \\
\text { constant for moderate } \\
\text { overload (hours) }\end{array}$ \\
\hline Rated_Load & 1200 MVA & $\begin{array}{l}\text { Rated load of the } \\
\text { transformer }\end{array}$ \\
\hline Life_Expectancy & 20.5 years & $\begin{array}{l}\text { Expected life of the } \\
\text { transformer (years) }\end{array}$ \\
\hline
\end{tabular}

Table 3. Numeric parameter inputs to the IEEE thermal model as implemented in the FW-PHM Suite 


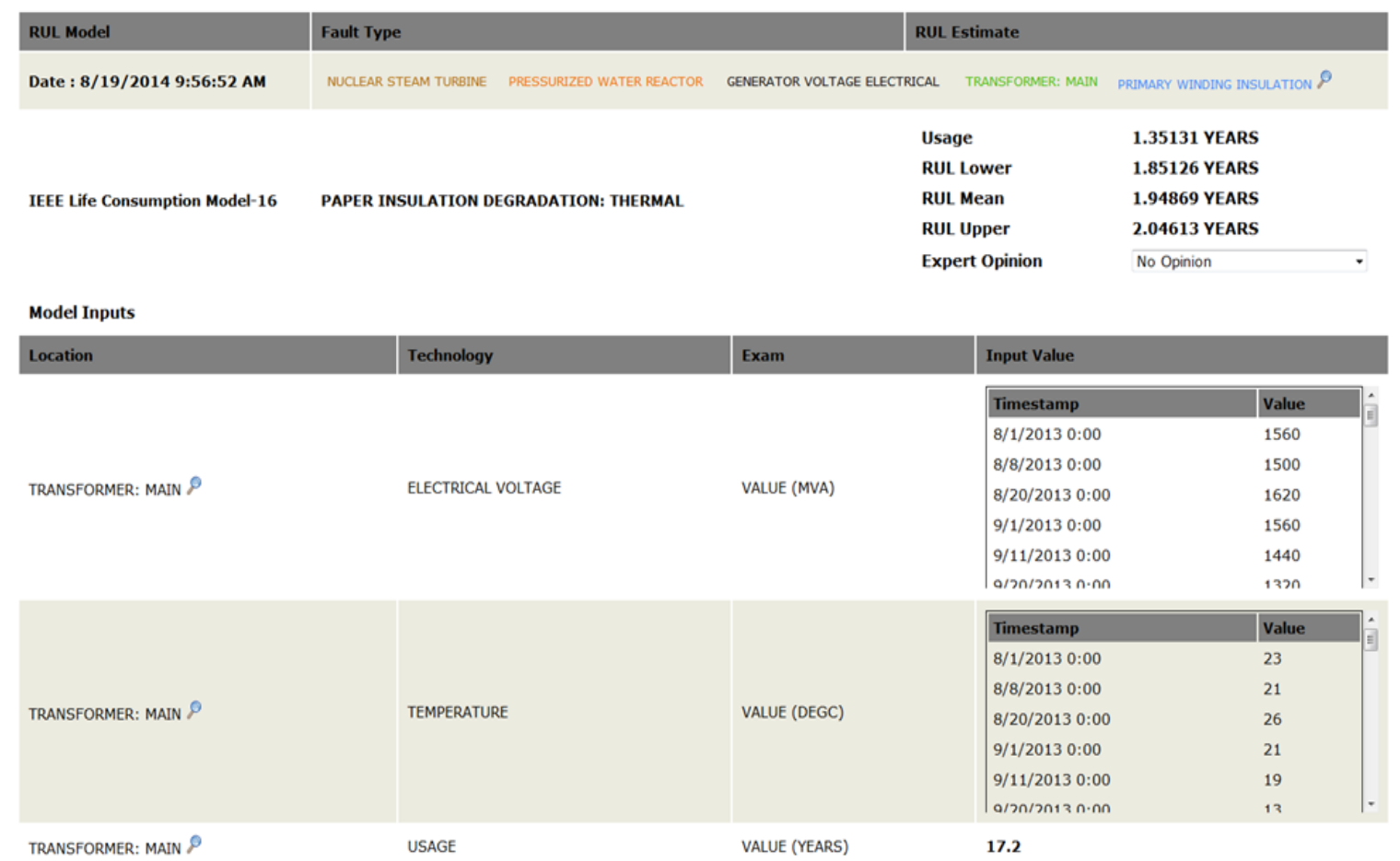

Figure 10. RUL estimate for the GSU transformer based on the IEEE life consumption model

\section{RESEARCH SigNIFICANCE}

Diagnosing a potential problem (fault) in a NPP can take significant time and plant resources. There is an immediate need to optimize plant resources to support productive and economical operation of the current fleet of nuclear plants. At the same time, the challenges of aging subject matter experts and knowledge drain are preventing nuclear plants from maintaining economic competitiveness in the energy market.

By embracing advanced sensors and instrumentation, the nuclear industry can alleviate some of the burden of time consuming work with the use of remote monitoring and automated diagnosis and prognosis of component health. Advanced sensors and instrumentation will also enhance the safety of NPPs. The online monitoring research presented in this paper enables:

- Mitigation of equipment failure. Timely identification of developing faults allows plant staff to anticipate and avoid equipment issues that could limit plant production or reduce asset life.

- Improved reliability and productivity. An accurate diagnosis and prognosis will help develop effective troubleshooting plans for the plants that can be used to reduce unexpected failures, thereby reducing unplanned outages.

- Optimization of management. Creation of a formal record of industry-wide diagnostic experiences. When a systematic cause is observed, plants can change their response accordingly to minimize the problem.

- Knowledge expansion. The system learns through continuous database development and consolidation of information across the fleet. The knowledge of experienced engineers (i.e., domain knowledge) and mining the volume of information gathered from sensors and instrumentation installed on plant assets will enhance the accuracy of future diagnosis and prognosis.

EPRI is working with nuclear utilities to install, test, and implement the automated diagnosis and prognosis capabilities of the FW-PHM Suite. EPRI is also leading the PHM Asset Fault Signature Development Users' Group that involves industrial experts and research entities working on developing fault signatures for different active plant assets.

The research presented in this paper has the potential to be consolidated in the integrated operation of a nuclear power plant. This research would support the real-time condition monitoring of data from different sources that include fixed sensors installed on plant equipment, mobile technologies used by field workers, etc., to perform automated diagnosis and prognosis. The resulting plant health information can be readily shared with different plant entities such as the plant engineering system health program, troubleshooting and root cause teams, original equipment manufacturers and technical consultants, etc. 


\section{ConClusions ANd Future Research}

The paper presented research activities at Idaho National Laboratory related to online monitoring of active assets in NPPs. This included:

- Introduction of the FW-PHM Suite software

- Research, development, and implementation of diagnostic models for GSUs in the Asset Fault Signature Database of the FW-PHM Suite

- Diagnostic capability of the FW-PHM Suite using the Diagnostic Advisor

- Research, development, and implementation of the Type II prognostic models in the Remaining Life Database of the FW-PHM Suite

- Prognostic capability of the FW-PHM Suite using the RUL Advisor to estimate the GSU winding insulation lifetime.

Ongoing research activities involve researching, developing, and implementing diagnostic and prognostic models for large electrical motors in NPPs. To date, the FW-PHM Suite software has been used to perform diagnosis and prognosis for active assets in NPPs. Research efforts are expanding to develop and implement diagnostic and prognostic models for passive nuclear assets. In addition, future research should focus on developing meaningful uncertainty quantification methods for RUL models implemented in the Remaining Life Database.

\section{ACKNOWLEDGEMENTS}

This research was made possible through funding by the U.S. Department of Energy (DOE) Light Water Reactor Sustainability Program. We are grateful to Richard Reister of the DOE and Bruce Hallbert, Kenneth Thomas, and Kathryn McCarthy of Idaho National Laboratory (INL) for championing this effort. We thank Bhavin Desai and Wayne Johnson (EPRI) for their time and efforts validating the generator step-up transformer fault signatures. We are grateful to Rahul Palnitkar (Expert Microsystem, Inc.) and Kirk Fitzgerald (INL) for providing technical support with the FW-PHM Suite. We also thank Heather Medema (INL) for her editing support.

\section{DISCLAIMER}

This information was prepared as an account of work sponsored by an agency of the U.S. Government. Neither the U.S. Government nor any agency thereof, nor any of their employees, makes any warranty, expressed or implied, or assumes any legal liability or responsibility for the accuracy, completeness, or usefulness, of any information, apparatus, product, or process disclosed, or represents that its use would not infringe privately owned rights. References herein to any specific commercial product, process, or service by trade name, trade mark, manufacturer, or otherwise, does not necessarily constitute or imply its endorsement, recommendation, or favoring by the U.S. Government or any agency thereof. The views and opinions of authors expressed herein do not necessarily state or reflect those of the U.S. Government or any agency thereof.

\section{REFERENCES}

Aba-Siada, A. (2011). Correlation of Furan Concentration and Spectral Response of Transformer Oil Using Expert Systems. IEEE/IET Science, Measurement and Technology, 5(5), pp. 183-188. doi: 10.1049/ietsmt.2011.0017

Abu-Elanien, A. E. B., \& Salama, M. M. A. (2010). Asset Management Techniques for Transformers. Electric Power Systems Research, 80(4), pp. 456-464. doi:10.1016/j.epsr.2009.10.008

Agarwal, V., Lybeck, N. J., Pham, B. T., Bickford, R., \& Rusaw, R. (2015). Implementation of Remaining Useful Lifetime Transformer Models in the Fleet-Wide Prognostic and Health Management Suite. Proceedings of $9^{\text {th }}$ International Conference on Nuclear Plant Instrumentation, Control, \& Human-Machine Interface Technologies (NPIC-HMIT), February 23-26, Charlotte, NC.

Agarwal, V., Lybeck, N. J., Bickford, R., \& Rusaw, R. (2014). Development of Asset Fault Signatures for Prognostic and Health Management in the Nuclear Industry. Proceedings of IEEE Annual Conference on Prognostics and Health Management, June 21-24, Spokane, WA.

Agarwal, V., Lybeck, N. J., \& Pham, B. T. (2014). Diagnostic and Prognostic Models for Generator StepUp Transformers. INL/EXT-14-33124, Idaho National Laboratory, Idaho Falls, USA.

Agarwal, V., Lybeck, N. J., Pham, B. T., Rusaw, R., \& Bickford, R. (2013). Online Monitoring of Assets in Nuclear Industry. Proceedings of Annual Conference on Prognostics and Health Management, October 14-17, New Orleans, LA.

Agarwal, V., Lybeck, N. J., Matacia, L., \& Pham, B. T. (2013). Demonstration of Online Monitoring for Generator Step-up Transformers and Emergency Diesel Generators, INL/EXT-13-30155, Idaho National Laboratory, Idaho Falls, USA.

Baird, P. J., Herman, H., Stevens, G. C., \& Jarman, P. N. (2006). Non-destructive Measurement of the Degradation of Transformer Insulation Paper. IEEE Transactions on Dielectrics and Electrical Insulation, 13(1), pp. 309-318. doi: 10.1109/TDEI.2006.1624275

Coble, J. B., (2010). Merging Data Sources to Predict Remaining Useful Life - An Automated Method to Identify Prognostic Parameters. Doctoral Dissertation, The University of Tennessee, Knoxville, USA.

Chendong, X. (1991). Monitoring Paper Insulation Aging by Measuring FurFural Contents in Oil. Proceedings of 
7th International Symposium on High Voltage Engineering, Dresden, Germany, August 28-30, 1991, pp. 139-142.

Cheim, L., Platts, D., Prevost, T., \& S. Xu. (2012). Furan Analysis for Liquid Power Transformers. IEEE Electrical Insulation, 28(2), pp. 8-21. doi: 10.1109/MEI.2012.6159177

Duval, M. (2002). A Review of Faults Detectable by Gasin-Oil Analysis in Transformers. IEEE Electrical Insulation Magazine, 18(3), pp. 8-17. doi: 10.1109/MEI.2002.1014963

Electric Power Research Institute (EPRI) (2012). Fleet-Wide Prognostics and Health Management Application Research. Report 1026712. Electric Power Research Institute, Charlotte, NC, USA.

Electric Power Research Institute (EPRI) (2011). EPRI Power Transformer Guidebook Development: The Copper Book, Report 1021892, Electric Power Research Institute, Palo Alto, CA, USA.

Emsley, A.M., \& Stevens, G.C. (1994). Review of Chemical Indicators of Degradation of Cellulosic Electrical Paper Insulation in Oil-filled Transformers. IEE Proceedings on Science, Measurement, and Technology, 141(5), pp. 324-334. doi: 10.1049/ip-smt:19949957

Emsley, A.M., Xiao, X., Heywood, R.J., \& Ali, M. (2000). Degradation of Cellulosic Insulation in Power Transformers - Part 2: Formation of Furan Products in Insulating Oil. IEE Proceedings on Science, Measurement, and Technology, 147(3), pp. 110-114. doi: 10.1049/ip-smt:20000259

Hohlein, I., \& Kachler, A. (2005). Aging of Cellulose at Transformer Service Temperatures - Part 2. Influence of Moisture and Temperature on Degree of Polymerization and Formation of Furanic Compounds in Free-breathing Systems. IEEE Electrical Insulation Magazine, 21(5), pp. 20-24. doi: 10.1109/MEI.2005.1513426

Institute of Electrical and Electronics Engineers (IEEE) (2012). IEEE Guide for Loading Mineral Oil Immersed Transformers and Step Voltage Regulators. IEEE Std C57.91 2011, New York, March.

Institute of Electrical and Electronics Engineers (IEEE) (2008). IEEE Guide for Interpretation of Gases Generated in Oil-Immersed Transformers. In IEEE Standards C57.104 by IEEE Power \& Energy Society.

Johnson, P. (2012). Fleet wide asset monitoring: Sensory data to signal processing to prognostics. Proceedings of Annual Conference of the Prognostics and Health Management Society, September 23-27, Minneapolis, MN. ISBN-978-1-036263-05-9.

Johnson, P. (2014). Lessons Learned in Fleet wide Asset Monitoring of Gas Turbines and Supporting Equipment in Power Generation Applications. Proceedings of European Conference of the Prognostics and Health Management Society, July 8-10, Nantes, France. ISBN978-1-936263-16-5.
Medina-Oliva, G., Voisin, A., Monnin, M., Peysson, F., \& Leger, J. B. (2012). Prognostic assessment using fleetwide ontology. Proceedings of Annual Conference of the Prognostics and Health Management Society, September 23-27, Minneapolis, MN. ISBN-978-1036263-05-9

Monnin, M., Voisin, A., Leger, J., \& Lung, B. (2011). Fleetwide health management architecture. Proceedings of Annual Conference of the Prognostics and Health Management Society, September 25-29, Montreal, Quebec, Canada. ISBN-978-1-936263-03-5.

Monnin, M., Abichou, B., Voisin, A., \& Mozzati, C. (2011). Fleet historical case for predictive maintenance. Proceedings of International Conference on Surveillance 6, October 25-26, Compiegne, France.

Lundgaard, L. E., Hansen, W., \& Ingebrigtsen, S. (2008). Ageing of Mineral Oil impregnated Cellulose by Acid Catalysis. IEEE Transactions on Dielectrics and Electrical Insulation, 15(2), pp. 540-546. doi: 10.1109/TDEI.2008.4483475

Lybeck, N. J., Agarwal, V., Pham, B. T., Medema, H., \& Fitzgerald, K. (2012). Online monitoring technical basis and analysis framework for large power transformers. INL/EXT-12-27181. Idaho National Laboratory, Idaho Falls, USA.

Patrick, R., Smith, M. J., Byington, C. S., Vachtsevanos, G. J., Tom, K., \& Ly, C. (2010). Integrated software platform for fleet data analysis, enhanced diagnostics, and safe transition to prognostics for helicopter component CBM. Proceedings of the Annual Conference of the Prognostics and Health Management Society, October 13-16, Portland, OR. ISBN-978-1936263-01-1.

Pham, B. T., Lybeck, N. J., and Agarwal, V. (2012). Online Monitoring Technical Basis and Analysis Framework for Emergency Diesel Generators: Interim Report for FY 2013. INL/EXT-12-27754, Idaho National Laboratory, Idaho Falls, USA.

Umiliacchi, P., Lane, D., \& Romano, F. (2011). Predictive maintenance of railway subsystem using an Ontology based modeling approach. Proceedings of $9^{\text {th }}$ World Conference on Railway Research, May 22-26, Lille, France.

Wang, T., Yu, J., Siegel, D., \& Lee, J. (2008). A similaritybased prognostics approach for remaining useful life estimation of engineered systems. Proceedings of International Conference on Prognostics and Health Management, October 06-09, Denver, CO.

World Nuclear Association, (2015). Nuclear Power in the USA. URL: www.world-nuclear.org/info/countryprofile/countries-T-Z/USA--Nuclear-Power/

YouTube Video, (2014). Online Monitoring for Improved Power Plant Equipment Operating Life and Productivity, EPRI, 2012.

http://www.youtube.com/watch? $v=8 J C c h y d W l c g \&$ feature $=$ c4-overview\&list $=$ UUctcciH1NrAGpwMnKwvnLgQ 
Zhang, X., \& Gockenbach, E. (2008). Asset-Management of Transformers Based on Condition Monitoring and Standard Diagnosis. IEEE Electrical Insulation Magazine, 24(4), pp. 26-40. doi: 10.1109/MEI.2008.4581371

\section{BIOGRAPHIES}

Vivek Agarwal is a Research Scientist at Idaho National Laboratory, Idaho Falls, ID. He holds a Ph.D. in Nuclear Engineering from Purdue University, M.S. in Electrical Engineering from The University of Tennessee, Knoxville, and B.S. in Electrical Engineering from University of Madras. He serves on the Editorial Board of Journal of Pattern Recognition Research as a Section Editor. His research interests include online monitoring, machine learning, wireless sensor networks, signal and image processing, inverse problems, and battery modeling.

Nancy J. Lybeck is a data analyst at Idaho National Laboratory, Idaho Falls, ID. She holds a Ph.D. in Mathematics from Montana State University. She currently serves as the technical lead for INL's Nuclear Data Management and Analysis System. Prior to joining INL, she worked in the prognostics industry. Her research interests include numerical analysis, applied mathematics, diagnosis, and prognosis.

Binh T. Pham is a Research Scientist at Idaho National Laboratory, Idaho Falls, ID. She received her Ph.D. and M.S. in Electronics Engineering from Moscow Power Engineering Institute, Russia in 1992 and 1986, respectively. Her research interests include quantitative modeling, statistical modeling, and programming and computer simulation.

Richard Rusaw is a Senior Project Manager in the nuclear sector at the Electric Power Research Institute. He received his B.S. in nuclear engineering from University of Michigan in 1979, his MBA from University of North Carolina Charlotte in 1983. He is a registered PE in the state of South Carolina. At EPRI, his responsibilities are focused on instrumentation and control (I\&C) with a high degree of specialization in monitoring technologies and system reliability. Prior to joining EPRI, he spent 25 years at Duke Power as an I\&C engineer with a wide range of responsibilities supporting Oconee, McGuire, and Catawba nuclear power plants. His current research interests include diagnostic and prognostics software, development of advanced sensors for nuclear applications, advanced information technologies for plant productivity, reliability, and Long-Term Operation.

Randall Bickford is Expert Microsystems' President and Chief Technology Officer. He holds a B.S. in chemical Engineering from University of California, Davis. He is a recognized worldwide expert in Prognostic and Health Management technology. He is one of the industry's pioneers and holds multiple patents in the areas of pattern recognition, fault detection, diagnostics, and prognostics. Prior to founding Expert Microsystems, he worked in the aerospace industry where he developed advanced diagnostic and digital control technologies for space propulsion systems. 